\title{
The Implementation of the Differentiated Instruction in Higher Education: A Research Review
}

\author{
Maria Darra ${ }^{1} \&$ Eurydice-Maria Kanellopoulou, ${ }^{1, *}$ \\ ${ }^{1}$ Department of Primary School Education, University of the Aegean, Dimokratias 1, Rhodes \\ 85132, Greece \\ *Corresponding author: Department of Primary School Education, University of the Aegean, \\ Dimokratias 1, Rhodes 85132, Greece. E-mail: evikanell@gmail.com
}

Received: August 20, 2019 Accepted: September 20, 2019 Published: September 25, 2019

doi:10.5296/ije.v11i3.15307 URL: https://doi.org/10.5296/ije.v11i3.15307

\begin{abstract}
Meeting the diverse and various needs of learners, who come from different cultural and social environments, imposes changes in a modern education system through the implementation of new teaching approaches and practices, such as differentiated instruction. This literature review examines 16 studies regarding differentiated instruction in higher education which have taken place during the last decade. The results of the research revealed that differentiated instruction contributes to mobilizing preservice teachers, improving their performance and developing positive attitudes and beliefs of trainees and educators in higher education. There is also a need for further research regarding the effectiveness of the implementation of differentiated instruction in higher education, especially in Greece, where no relevant research has been conducted, compared to the international field.
\end{abstract}

Keywords: differentiated instruction; higher education; basic teacher education 


\section{Mll Macrothink}

\section{Introduction}

In a modern educational system, educators are asked to address the diverse and various needs of learners who come from different cultural and social environments. Differentiated instruction is a teaching practice that focuses on learners and aims to mitigate inequalities and differences between them as they have different abilities, skills and learning styles (Chamberlin \& Powers, 2010).

In particular, according to Tomlinson (2001), differentiated instruction is an approach to organizing teaching that can offer learners a variety of learning choices that meet their different needs. Trainees can understand the content in different ways, process ideas and show what they have learned. The adoption of differentiated instruction incorporates a variety of approaches, principles, organization, teaching and assessment that allow educators to move away from the traditional way of teaching which focuses on teacher and frontline teaching and leads many learners to failure (Dosch \& Zidon, 2014). Differentiated instruction modifies curricula, teaching methods, learning activities and assessments to maximize learning effectiveness (Subban, 2006; Tomlinson, 1999).

The implementation of differentiated instruction in higher education has been investigated in a limited number of studies, compared to the number of studies carried out in secondary and mainly in primary education (Dosch \& Zidon, 2014; Tulbure, 2011), suggesting that many primary teachers use differentiated instruction, less in secondary and even fewer in higher education. The reasons for the limited implementation of this particular teaching approach in higher education are due to the large number of student divisions, the number of contact hours that are minimal as well as the time required to plan various ways of evaluating them which are time consuming and difficult for teachers who, in addition to teaching, are in charge of research tasks (Ernst \& Ernst, 2005).

In these few studies, which were conducted to investigate the contribution of differentiated instruction in higher education, there was a significant academic performance among students who were taught differentiated instruction compared to those who were taught traditional teaching (Graham, 2009). However, further studies are needed to investigate the contribution of this educational approach to students' academic success.

Tulbure (2011) in her research on the relationship of differentiated instruction with students' learning styles in higher education, presents the quantitative empirical studies that she identified over 25 years (1985-2010) by grouping them according to results in three categories presented in Table 1. 
Table 1. Empirical Studies Focusing on Differentiated Instruction, According to a Research by Tulbure (2011)

\begin{tabular}{ll}
\hline Categories of result & Empirical studies \\
\hline & Abraham (1985) \\
$\begin{array}{l}\text { Differentiating instruction upon personal } \\
\text { learning styles leads to an improvement }\end{array}$ & Bajraktarevic, Hall \& Fullick (2003) Dunn et \\
in the level of learning results & Easter (1994) \\
& Felder (1993) \\
& Ford \& Chen (2001) \\
& Marshall (1991) \\
& Mickler and Zippert (1987) \\
& Nelson et al. (1993) \\
& Tulbure (2010) \\
\hline Differentiating the strategies of & Akdemir \& Koszalka (2008) \\
instruction upon learning styles does not & Cook, Thompson, et al. (2009) \\
affect the level of learning & Massa \& Mayer (2006) \\
\hline The lack of concordance between & Baker et al. (1988) \\
learning styles and didactic strategies & Cavanagh \& Coffin (1994) \\
stimulates and makes the learning process & Kowoser \& Berman (1996) \\
flexible & \\
\hline
\end{tabular}

\section{Differentiated Instruction: A Theoretical Approach}

Higher education curricula for future teachers are designed to develop the appropriate pedagogical skills and competencies to meet students' different classroom needs. However, this goal is not always achieved, as some preservice teachers still face serious problems in bridging the gap between theory and effective classroom practice, making it necessary for the University curricula to be adapted (Joseph, 2013). Achieving this adjustment requires the implementation of differentiated instruction which is an innovative educational strategy, based according to Tomlinson and Imbeau (2010) on the fact that students of the same age differ in their readiness to learn, their interests, how they learn, their experiences and living conditions. The differences between them are significant enough to greatly influence what they need to learn. Students will also learn better when they can make connections between the curriculum and their interests and life experiences, and finally the educational process aims to maximize each child's ability.

A key principle of differentiated instruction is the notification by the trainer to the trainees of what is necessary for them to learn about a subject in order to link curriculum and teaching with assessment. In a differentiated classroom, evaluation is ongoing and serves to feedback the teaching. Teachers also accept differences between learners and respond with the expectation that they will understand what they can do (Chamberlin \& Powers, 2010). Students can participate in teamwork that cultivates their critical thinking and fosters their personal development through collaboration with each other as well as with educators. The 
latter form various groups flexibly and direct discussions throughout the classroom. Trainees work in these groups based on their readiness, interests, or learning profiles. Teaching is also organized to address learners' different preferences by making appropriate use of space, time and logistical infrastructure (Chamberlin \& Powers, 2010).

The design of differentiated instruction is centered on the student and the curriculum (Panteliadou, 2008). The first axis, which focuses on the particular needs of each student, is distinguished by readiness, interest and learning style (Tomlinson, 2001). In more detail, readiness reflects the cognitive level of each student, who by making appropriate use of his / her abilities, skills and inclinations, can, with the implementation of differentiated instruction, move to the next level of knowledge (Kosivaki, 2002), according to the theory of zone of proximal development by Vygotsky (1986). Also, the interests of the student through differentiated instruction are more activated by his motivation due to his active involvement in learning. The learning style characterizes the student's learning style and according to Gardner (1993) relates to his type of intelligence.

The second axis focuses on the teaching that is defined by the curriculum and includes the content, its process, the final product and the learning environment. By varying the content, teachers modify or adjust students' access to educational material to facilitate their acquisition of knowledge and encourage them to learn at their own pace within set deadlines. Process differentiation involves providing students with a variety of activities that are offered to help students understand what they need to learn (Tomlinson, 2001). The process is the way with which the content or curriculum is taught and the different ways that students are invited to learn. By differentiating the final product, students can demonstrate or present what they have learned in a variety of ways which match their learning abilities and interests (Anderson, 2007). The differentiation of the environment in which a student learns must be adapted to the individual learning styles, preferences and needs of students.

Differentiated instruction has many benefits for both the learner and the educator. This teaching practice enhances collegiality and cooperation, provides motivations and facilitates students to link theory to practice. With this connection students improve their knowledge and discover new interests (Santangelo \& Tomlinson, 2009). With differentiated instruction, students are at the center of the teaching process, their needs and preferred ways of learning are met and their success is assured (Tulbure, 2011). In addition, differentiated instruction enables educators to respond rather than react to students' unique and individual personalities, backgrounds, and abilities (Anderson, 2007).

However, in some studies obstacles appear as far as the implementation of differentiated instruction is concerned. These include lack of administrative support (Hertberg-Davis \& Brighton, 2006), fear of lowering student scores (Tieso, 2004), lack of time to design differentiated instruction (Hertberg-Davis \& Brighton, 2006) and uncertainty about students' reaction to it (Knopper \& Fertig, 2005). Despite these difficulties, differentiation becomes more effective when teachers are motivated and provided with the appropriate conditions to implement differentiated instruction (Tomlinson, 2005). 


\section{Purpose and Research Questions}

The main purpose of the present study is to investigate the effectiveness of the implementation of differentiated instruction on the continuous improvement of the basic education of preservice teachers in higher education through the analysis of 16 studies from the international field conducted over the last decade (2008-2018). In particular, the contribution of differentiated instruction in mobilizing and improving the performance of preservice teachers, the attitudes and beliefs of preservice teachers as well as their educators about the use of this particular teaching approach, the advantages, disadvantages and its effective implementation in teacher basic education are examined.

Indicative questions put to the investigation and which the research will attempt to answer are the following:

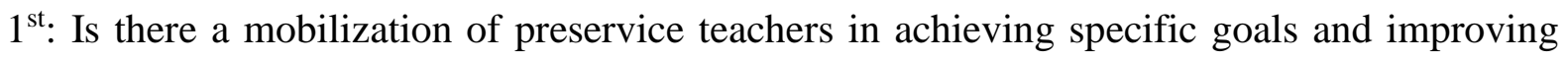
their performance as a result of implementing differentiated instruction?

$2^{\text {nd. }}$ Do preservice teachers and their educators form more positive beliefs and attitudes as a result of implementation of differentiated instruction?

$3^{\text {rd }}:$ Are there advantages from the implementation of differentiated instruction?

$4^{\text {th: }}$ Are there difficulties in implementing differentiated instruction to influence the intention of preservice teachers to use it? If so, which ones?

$5^{\text {th: }}$ What are the conditions and procedures for effective implementation of differentiated instruction?

$6^{\text {th: }}$ What is the methodological design used in the studies under consideration?

$7^{\text {th. }}$ In which subjects was differentiated instruction implemented in higher education and what was its purpose?

\section{Method}

For the purposes of the present study, the literature review was conducted via search engines in databases: google scholar, ERIC, Taylor \& Francis with the keywords: differentiated instruction in higher education. These databases were selected because of their accessibility and therefore their selection is a limitation for the present research. The bibliographic review includes 16 research articles and doctoral theses, published over the last decade (2008 - 2018) in the international field and related to our research questions. Greek literature has identified a research carried out in Cyprus.

\section{Results of the Research}

The results of the research initially include data regarding the number of studies examined per year, their country of origin, the type and size of the sample. The results of the present 
study are then presented in detail by research question.

Table 2 summarizes the main results of the literature review of researches as far as the implementation of differentiated instruction in higher education is concerned.

Table 2. Main Results of the Literature Review of Researches on the Implementation of Differentiated Instruction in Higher Education

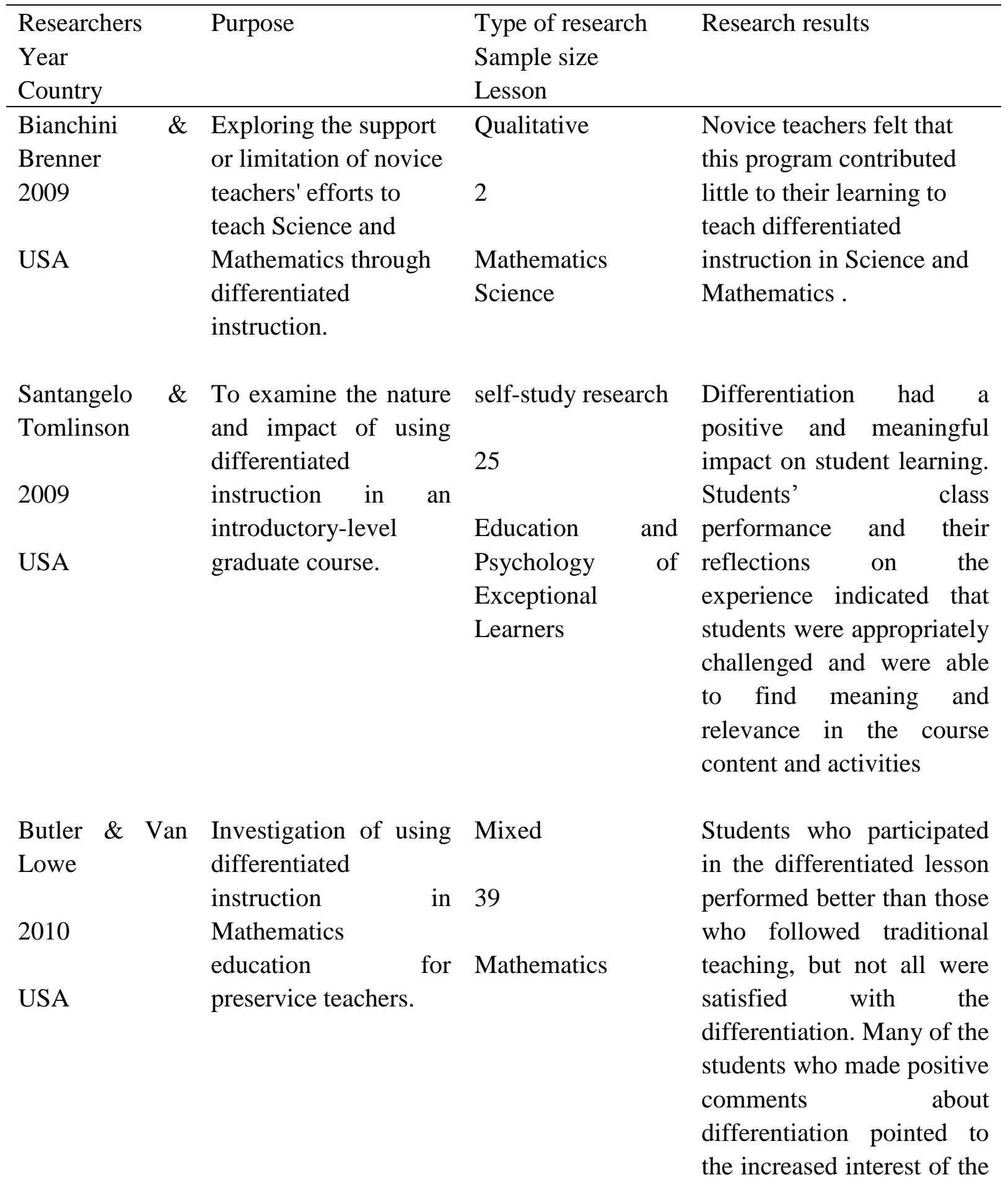




$\begin{array}{lll}\begin{array}{l}\text { Chamberlin \& } \\ \text { Powers }\end{array} & \begin{array}{l}\text { Investigation of using } \\ \text { differentiated } \\ \text { instruction in an }\end{array} & \text { Mixed } \\ \text { undergraduate } & \text { 224 students \& } \\ \text { Mathematics course } & \\ \text { USA } & \begin{array}{l}\text { for addressing such } \\ \text { concerns and there by } \\ \text { improving students } \\ \text { mathematical learning }\end{array} \\ & \begin{array}{l}\text { Investigation } \\ \text { students perceptions of } \\ \text { differentiated } \\ \text { instruction of the }\end{array} \\ \text { 2010 } & \text { Science course. } & \text { Science } \\ \text { Canada } & \end{array}$

$\begin{array}{lll}\begin{array}{l}\text { Symeonidou \& } \\ \text { Kyriakides }\end{array} & \begin{array}{l}\text { Investigating the Teaching } \\ \text { degree of students' } \\ \text { ability in planning and }\end{array} \\ 2010 & \begin{array}{l}\text { adapting lessons by } \\ \text { implementing } \\ \text { differentiated } \\ \text { instruction. }\end{array} & \\ \text { Cyprus } & \text { School Experience }\end{array}$

$\begin{array}{lll}\begin{array}{l}\text { Williams-Black, } \\ \text { Bailey }\end{array} \text { Investigating how } & \text { Qualitative } \\ \text { Lawson } & \begin{array}{l}\text { university professors } \\ \text { are differentiating } \\ \text { instruction in their }\end{array} & 6 \\ 2010 & \begin{array}{l}\text { undergraduate and } \\ \text { graduate level reading } \\ \text { courses. }\end{array} & \text { Reading } \\ \text { USA } & & \end{array}$

teacher, which influenced them positively, while others thought that differentiation was a waste of time.

Students receiving differentiated instruction experienced greater gains in their mathematical understandings

Students understand the potentials and difficulties of implementing differentiated instruction, which requires time, effort, careful planning, knowledge of differentiated instruction, and flexibility on the part of the teacher.

There are significant shortcomings in the implementation of differentiated instruction and improvement in the organization and content of undergraduate students teaching is needed to overcome the difficulties of differentiation and to know how to successfully implement it.

The study identified various methods for how teachers differentiated content, process, product and environment in the graduate program and undergraduate courses. 


\section{Mok}

2012

Tricarico
$\&$ Yendol
Hoppey

Hoppey

2012

USA

Joseph

2013

Trinidad
Investigating the implementation of

differentiated

instruction with lab

exercises in an

undergraduate

programming course

of Computer science

and recording students

perceptions of them.
Mixed

267

Computer science

\section{Investigating teachers' Qualitative}

differentiated

instruction.

\section{Alternative}

Certification

Programs

$\begin{array}{lrl}\text { Investigating } & \text { what } & \text { Mixed } \\ \text { preservice } & \text { and in } & \\ \text { service } & \text { trained } & 379 \\ \text { teachers } & \text { understand } & \end{array}$
instruction and the extent to which they practiced it in their classrooms.
Findings reveal that these tiered exercises are generally very well received by the students and preferred over their traditional "one size fits all" counterparts. Although the study does not show that tiered exercises have improved proficiency or scores, it does seem to indicate higher student engagement and motivation levels.

Some teachers are more capable of reflecting and taking immediate initiatives in their classrooms, especially as they appear to be able to monitor learners' behavior, while others show insecurity in taking action.

$58 \%$ of respondents understood the concept of differentiated instruction. However, the majority of teachers did not differentiate content and product in their classrooms. The study also highlighted various difficulties in implementing differentiated instruction, such as lack of time for planning, limited space for teamwork, and lack of administrative support.

The team that implemented differentiated instruction perceived its methods as beneficial to their learning, 
USA

Dack

2015

USA

Evans-Hellman
\& Haney

2017

USA

Jackson

Evans

2017

USA instruction in higher education.

Investigating how Qualitative

novice teachers

implement the model 2

of Tomlinson's

differentiated

instruction to a teacher

preparation lesson.

Language

Psychology
Mathematics

2019, Vol. 11, No. 3

and this team performed

better than the traditional

teaching team on

assignments and exams.

The trainers gained new knowledge to differentiated instruction as they deepened their holistic

Arts, understanding of the model and resolved their misunderstandings.

Diffenentiation is important for the professional and academic success of future students.

Research to record Quantitative students' familiarity and perceptions of differentiation and their intention to use it in their future classroom teaching.

\& Investigating the teaching experiences and expectations of two teachers who shaped their philosophy and practices of differentiated instruction in teacher education programs.

Turner, Solis \& Research for the Qualitative Kincade 2017 USA instructors' understanding of 20 differentiated instruction and their perceptions of the challenges of implementing it to large classes
218

No lesson reported

Qualitative

2

No lesson reported

Students' familiarity with differentiated instruction over time increases within the curricula, but there are differences between the programs.

It is clear from the reflection of the two teachers that differentiated instruction is focused on the student who is actively involved, is interrelated with the assessment and is required in teacher preparation programs.

Differentiated instruction in large classes at a research university is challenging. Moreover, instructors teaching large classes need a better understanding of differentiated instructional strategies and how to implement them. 
Chen \& Chen Research on students' Quasi-experimental Differentiation improved motivations, academic

2018

achievements,

60 mathematical achievement, attitudes and

Taiwan perceptions about Mathematics student learning motivation and teaching effectiveness. differentiated The results supported the effectiveness of instruction within a differentiated instruction in calculus curriculum. the curriculum.

Figure 1 shows the number of researches per year.

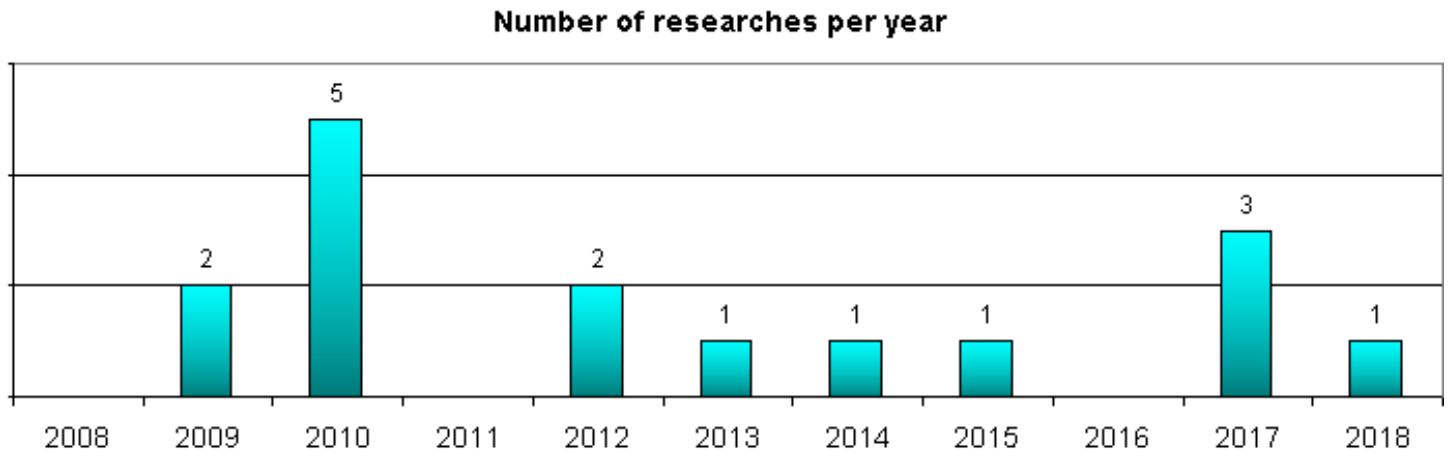

Figure 1. Number of Researches per Year

Figure 2 shows the number of researches internationally.

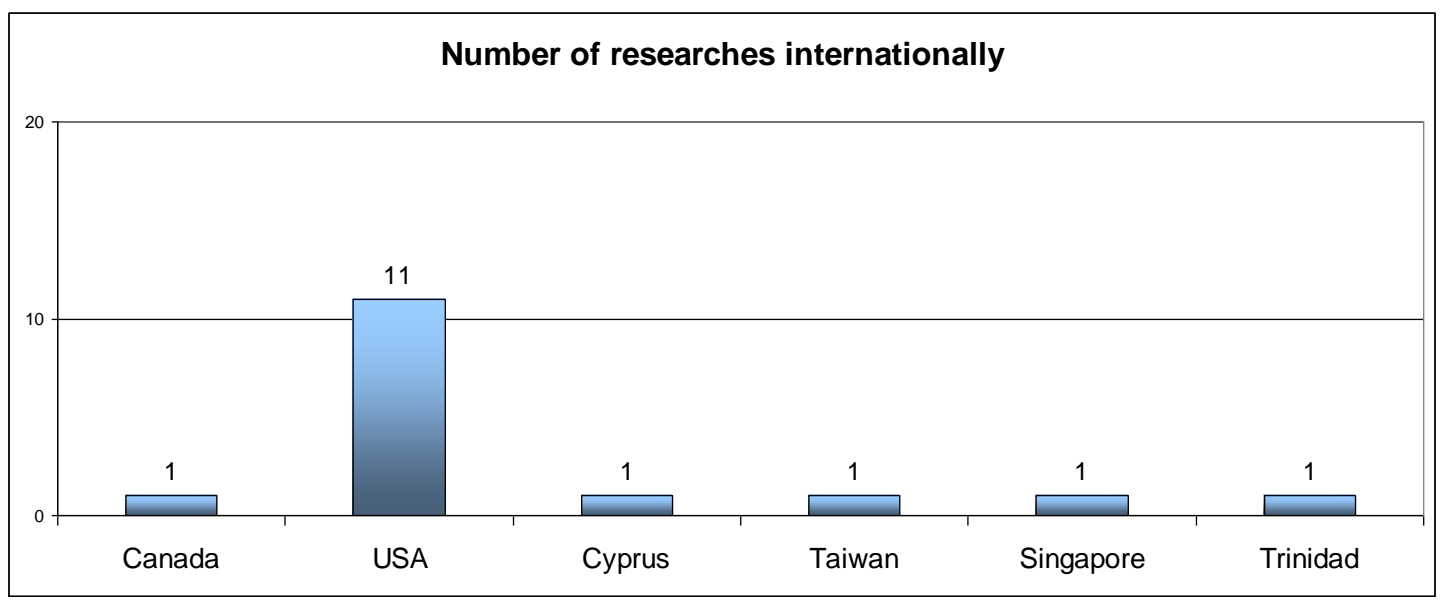

Figure 2. Number of Researches Internationally

Figure 3 shows the number of researches per type. 


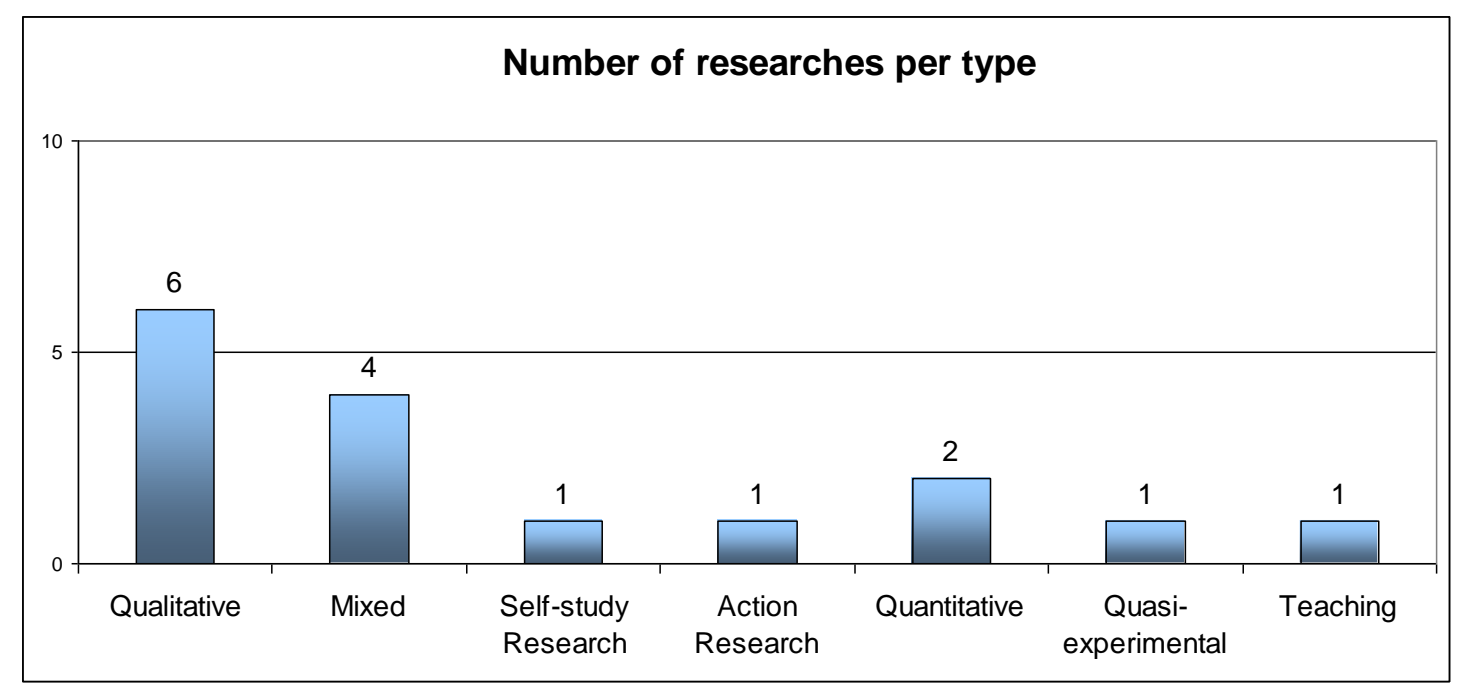

Figure 3. Number of Researches per Type

1st Research question: Is there a mobilization of preservice teachers in achieving specific goals and improving their performance as a result of implementing differentiated instruction?

As shown in Table 2, several researches $(37.5 \%, \mathrm{~N}=6)$ show that the implementation of differentiated instruction mobilizes preservice teachers to achieve specific goals and improve their performance (Santangelo \& Tomlinson, 2009; Butler \& Van Lowe, 2010; Chamberlin \& Powers, 2010; Dosch \& Zidon, 2014; Dack, 2015; Chen \& Chen, 2018). More specifically, students reported that differentiation had a positive and meaningful impact on their learning, performed better than those who followed traditional teaching and benefited the most. However, one study was found (6.25\%), which showed that while differentiated instruction provided students with incentives to learn, there was no improvement in their grades (Mok, 2012).

2nd Research question: Do preservice teachers and their educators form more positive beliefs and attitudes as a result of implementation of differentiated instruction?

According to the results of the research (Table 2) in some surveys $(25 \%, \mathrm{~N}=4)$ preservice teachers participating in the implementation of differentiated instruction formed more positive beliefs and attitudes (Santangelo \& Tomlinson, 2009; Joseph, 2013; Evans-Hellman \& Haney, 2017; Chen \& Chen, 2018). In particular, students understood better the concept of differentiated instruction and by increasing their motivation for learning as well as through reflection they supported the effectiveness of differentiated instruction in their curriculum. However, there are two researches (12.5\%), with the first recording that novice teachers felt that the program they participated in had little contribution to their learning to teach with differentiated instruction Science and Mathematics (Bianchini \& Brenner, 2009) and in second, not all students were satisfied with the implementation of differentiated instruction. Most of the students who made positive comments about differentiation pointed to the increased interest of the teacher, which influenced them positively, while others thought that 
differentiation was a waste of time (Butler \& Van Lowe, 2010).

Regarding the development of more positive beliefs and attitudes of preservice teachers educators, two studies $(12.5 \%)$ were identified, where the first found that educators gained new knowledge about teaching differentiation as they deepened their holistic understanding of the model and resolved their misunderstandings (Dack, 2015), while in the second differentiated instruction has been a challenge for educators as they need to better understand its educational strategies and ways of implementing them (Turner et al., 2017).

3rd Research question: Are there advantages from the implementation of differentiated instruction?

As shown in Table 2, most researches $(50 \%, \mathrm{~N}=8)$ refer to the advantages of implementing differentiated instruction (Santangelo \& Tomlinson, 2009; Butler \& Van Lowe, 2010; Williams-Black et al., 2010; Tricarico \& Yendol-Hoppey, 2012; Dosch \& Zidon, 2014; Dack, 2015; Jackson \& Evans, 2017; Chen \& Chen, 2018). Specifically, the benefits of differentiated instruction include focusing on the learner who is actively engaged in teaching, reflection, through which some teachers take direct initiatives in their classrooms, the increased interest of the teacher, the different methods in which teachers differentiate content, process, product and environment, effectiveness of teaching and the professional and academic success of preservice teachers.

4th Research question: Are there difficulties in implementing differentiated instruction to influence the intention of preservice teachers to use it? If so, which ones?

According to the research results (Table 2) in some surveys $(31.25 \%, \mathrm{~N}=5)$, difficulties in implementing differentiated instruction are recorded (Butler \& Van Lowe, 2010; Goodnough, 2010; Symeonidou \& Kyriakides, 2010; Tricarico \& Yendol - Hoppey, 2012; Joseph, 2013; Turner et al., 2017). The most important difficulties are the large number of classroom learners, the lack of time for careful planning of teaching, the limited space for teamwork, the difficulties in organizing and teaching content, the insecurity of taking initiatives and some administrative support.

5th Research question: What are the conditions and procedures for effective implementation of differentiated instruction?

Based on the results of the research (Table 2) in a few surveys $(18.75 \%, \mathrm{~N}=3)$ the conditions and procedures for effective implementation of differentiated instruction are recorded (Goodnough, 2010; Symeonidou \& Kyriakides, 2010; Joseph, 2013). More specifically, in these researches careful planning and organization of teaching, knowledge of differentiated instruction, availability of time, flexibility on the part of the teacher, and support from the administration are recorded as basic requirements and procedures for effective implementation of differentiated instruction.

6th Research question: What is the methodological design used in the studies under consideration?

The following table 3 presents the methodological design (type of survey, number and 
corresponding percentage of specific researches) of this study.

Table 3. Methodological Design

\begin{tabular}{lll}
\hline Type of researches & Researches & Percentages \\
\hline Qualitative & 4 & $25 \%$ \\
Mixed & 4 & $25 \%$ \\
Quantitative & 2 & $12,5 \%$ \\
Action Research & 1 & $6,25 \%$ \\
Quasi-experimental & 1 & $6,25 \%$ \\
Self-study research & 1 & $6,25 \%$ \\
Teaching & 1 & $6,25 \%$ \\
\hline
\end{tabular}

Regarding the sample size, as shown in Table 4, most researches used a sample consisting of fewer than 50 individuals. Three researches using a sample ranging from 50-100 individuals were also identified and four researches using a sample of 100 individuals and more.

Table 4. Sample Size

\begin{tabular}{lll}
\hline Sample size & Researches & Percentages \\
\hline Less than 50 people & 9 & $56,25 \%$ \\
From 50 to 100 people & 3 & $18,75 \%$ \\
More than 100 people & 4 & $25 \%$ \\
\hline
\end{tabular}

7th Research question: In which subjects was differentiated instruction implemented in higher education and what was its purpose?

Regarding the cognitive subjects on which differentiated instruction was implemented, as shown in Table 5, it is observed that most researches have been implemented to the Mathematics course (Bianchini \& Brenner, 2009; Butler \& Van Lowe, 2010; Chamberlin \& Powers, 2010; Dack , 2015; Chen \& Chen, 2018), followed by other courses such as Science (Bianchini \& Brenner, 2009; Goodnough, 2010), the Education and Psychology of Excellent Students (Santangelo \& Tomlinson, 2009), School Experience (Symeonidou \& Kyriakides, 2010), Reading (Williams-Black et al., 2010), Computer Science (Mok, 2012), Teacher Certification Programs (Tricarico \& Yendol - Hoppey, 2012), Educational Psychology (Dosch \& Zidon, 2014), Language Arts (Dack, 2015), Humanities and Social Sciences (Turner et al., 2017), Arts (Turner et al., 2017). Finally, there are three researches that do not mention the cognitive subjects in which differentiated instruction was implemented (Joseph, 2013; Evans-Hellman \& Haney, 2017; Jackson \& Evans, 2017). 
Table 5. Cognitive Subjects

\begin{tabular}{lll}
\hline Cognitive subjects & Number of researches & Percentages \\
\hline Mathematics & 5 & $31,25 \%$ \\
Science & 2 & $12,5 \%$ \\
Education and Psychology of Excellent Students & 1 & $6,25 \%$ \\
School Experience & 1 & $6,25 \%$ \\
Reading & 1 & $6,25 \%$ \\
Computer Science & 1 & $6,25 \%$ \\
Teacher Certification Programs & 1 & $6,25 \%$ \\
Educational Psychology & 1 & $6,25 \%$ \\
Language Arts & 1 & $6,25 \%$ \\
Humanities & 1 & $6,25 \%$ \\
Social Sciences & 1 & $6,25 \%$ \\
Arts & 1 & $6,25 \%$ \\
Do not mention the cognitive subject & 3 & $18,75 \%$ \\
\hline
\end{tabular}

Regarding the purpose of implementing differentiated instruction it appears that studies have investigated the effectiveness of implementing differentiated instruction in higher education (Bianchini \& Brenner, 2009; Santangelo \& Tomlinson, 2009; Butler \& Van Lowe, 2010; Tricarico \& Yendol - Hoppey, 2012; Dosch \& Zidon, 2014). More specifically, several studies focused on the perceptions of participating preservice teachers and their educators (Goodnough, 2010; Mok, 2012; Evans-Hellman \& Haney, 2017), while others examined the extent to which preservice teachers were familiar with the implementation of this particular teaching practice and the benefits they gained (Chamberlin \& Powers, 2010; Symeonidou \& Kyriakides, 2010; Williams-Black et al., 2010; Joseph, 2013).

\section{Discussion of Research Results}

Overall the average research per year from 2008-2018 is 1.6. All researches have been conducted internationally and the largest number of them have been conducted in the US ( $\mathrm{n}=$ 11), with the smallest number being carried out in other countries. In Greece, no research has been found on differentiated instruction in higher education.

Regarding the contribution of differentiated instruction in the mobilization of preservice teachers for the achievement of specific goals pursued and the improvement of their performance in higher education (first research question), the results of the present study show that differentiated instruction contributes to the mobilization of preservice teachers in achieving specific goals pursued and in improving their performance in higher education internationally (Santangelo \& Tomlinson, 2009; Butler \& Van Lowe, 2010; Chamberlin \& Powers, 2010; Dosch \& Zidon, 2014; Dack, 2015; Chen \& Chen, 2018). More specifically, the larger number of studies show that differentiation had a positive and significant impact on students' learning, as they benefited more and performed better than those students who 
followed traditional teaching. However, a study was found that showed that while differentiated instruction provided students with incentives to learn, there was no improvement in their grades (Mok, 2012). Mobilization of learners in achieving specific goals and improving their performance by implementing differentiated instruction is confirmed by other researchers in international literature (Ford \& Chen, 2001; Tomlinson et al., 2003).

Regarding the attitudes and beliefs of preservice teachers and their educators about the contribution of differentiated instruction in improving the effectiveness of internships (second research question), few studies have been identified internationally, where preservice teachers developed more positive beliefs and attitudes by participating in the implementation of differentiated instruction they (Santangelo \& Tomlinson, 2009; Joseph, 2013; Evans-Hellman \& Haney, 2017; Chen \& Chen, 2018). In particular, students were better aware of the concept of differentiated instruction and by increasing their learning motivation and through reflection they supported the effectiveness of differentiated instruction in their curriculum. However, there are two studies the first of which states that novice teachers felt that the program they took part in had little contribution to their learning to teach with differentiated instruction Science and Mathematics (Bianchini \& Brenner, 2009) and the second that they were not all students satisfied with the implementation of differentiated instruction. Most of the students who made positive comments about differentiation pointed to the increased interest of the teacher, which influenced them positively, while others thought that differentiation was a waste of time (Butler \& Van Lowe, 2010).

Also, as far as the attitudes and beliefs about the differentiated instruction of educators of preservice teachers in higher education are concerned, a small number of studies were found, which pointed out that the educators gained new knowledge about the differentiation of teaching as they deepened their holistic understanding of the model and resolved their misunderstandings (Dack, 2015). In addition, differentiated instruction has been a challenge for educators as they need to better understand its educational strategies and how they are implemented (Turner et al., 2017). The formulation of more positive beliefs and attitudes of preservice teachers and their educators as a result of the implementation of differentiated instruction is also demonstrated by other researchers (Tulbure, 2011).

Regarding the advantages of implementing differentiated instruction in higher education (third research question) several researches have been examined internationally (Santangelo \& Tomlinson, 2009; Butler \& Van Lowe, 2010; Williams-Black et al., 2010; Tricarico \& Yendol-Hoppey, 2012; Dosch \& Zidon, 2014; Dack, 2015; Jackson \& Evans, 2017; Chen \& Chen, 2018). More specifically, as advantages of differentiated instruction focusing on the learner who is actively involved in teaching, reflection, through which some teachers take direct initiatives in their classrooms, the increased interest of teachers, the various methods in which teachers differentiate the content, process, product and environment, the effectiveness of teaching and the professional and academic success of preservice teachers are recorded. These findings are also confirmed by other researchers (Tulbure, 2011).

Regarding the difficulties in implementing differentiated instruction in higher education 
(fourth research question), a small number of studies have been identified internationally (Butler \& Van Lowe, 2010; Goodnough, 2010; Symeonidou \& Kyriakides, 2010; Tricarico \& Yendol - Hoppey, 2012; Joseph, 2013; Turner et al., 2017). As major difficulties the large number of classroom learners, the lack of time for careful planning of teaching, the limited space for teamwork, the difficulties in organizing and teaching content, the insecurity of taking initiatives by some teachers and the lack of administrative support are mentioned. These findings are in line with the results of other researchers (Ernst \& Ernst, 2005; Tulbure, 2011).

Concerning the conditions and procedures for the effective implementation of differentiated instruction in higher education (fifth research question), few researches have been examined internationally (Goodnough, 2010; Symeonidou \& Kyriakides, 2010; Joseph, 2013). As the most important prerequisites for effective implementation of differentiated instruction careful planning and organization of teaching, knowledge of differentiated instruction, availability of time, flexibility on the part of the teacher and support from the administration are recorded. These findings are also documented in other relevant researches (Buck \& Cordes, 2005).

Regarding the methodological design used in the examined studies on differentiated instruction in higher education internationally (sixth research question) most researches implemented qualitative research (Bianchini \& Brenner, 2009; Williams-Black et al., 2010; Tricarico \& Yendol - Hoppey, 2012; Dack, 2015; Jackson \& Evans, 2017; Turner et al., 2017) and the mixed method (Butler \& Van Lowe, 2010; Chamberlin \& Powers, 2010; Mok, 2012; Joseph, 2013), while less the quantitative method (Dosch \& Zidon, 2014; Evans-Hellman \& Haney, 2017) and even less Action Research (Goodnough, 2010), Quasi-experimental (Chen \& Chen, 2018), Self-study research (Santangelo \& Tomlinson, 2009) and Teaching (Simeonidou \& Kyriakides, 2010). Regarding the sample size, most researches used a sample consisting of fewer than 50 individuals. Three researches using a sample ranging from 50-100 individuals were also identified and four researches using a sample of more than one hundred individuals.

Concerning the cognitive subjects in which differentiated instruction has been implemented in higher education internationally, and the purpose of its implementation, (seventh research question), it is observed that most researches have been implemented on the Mathematics course (Bianchini \& Brenner, 2009; Butler \& Van Lowe, 2010; Chamberlin \& Powers, 2010; Dack, 2015; Chen \& Chen, 2018), followed by other courses such as Science (Bianchini \& Brenner, 2009; Goodnough, 2010), the Education and Psychology of Excellent Student (Santangelo \& Tomlinson, 2009), School Experience (Symeonidou \& Kyriakides, 2010), Reading (Williams-Black et al., 2010), Computer Science (Mok, 2012), Teacher Certification Programs (Tricarico \& Yendol - Hoppey, 2012), Educational Psychology (Dosch \& Zidon, 2014), Language Arts (Dack, 2015), Humanities and Social Sciences (Turner et al., 2017) and the Arts (Turner et al., 2017). Finally, there are three studies that do not mention the cognitive subjects in which differentiated instruction was implemented (Joseph, 2013; Evans-Hellman \& Haney, 2017; Jackson \& Evans, 2017).

Regarding the purpose of implementing differentiated instruction it appears that the studies 
have investigated the effectiveness of implementing differentiated instruction in higher education (Bianchini \& Brenner, 2009; Santangelo \& Tomlinson, 2009; Butler \& Van Lowe, 2010; Tricarico \& Yendol - Hoppey, 2012; Dosch \& Zidon, 2014). More specifically, several studies have focused on the perceptions of participating preservice teachers and their educators (Goodnough, 2010; Mok, 2012; Evans-Hellman \& Haney, 2017) and some have examined the extent to which preservice teachers are familiar with the implementation of specific teaching practice and the benefits they gained (Chamberlin \& Powers, 2010; Symeonidou \& Kyriakides, 2010; Williams-Black et al., 2010; Joseph, 2013).

\section{Conclusions}

The review of the researches studied in the last decade, results in an average 1.6 per year with most of them being conducted in the US, while none in Greece.

In particular, regarding the mobilization of preservice teachers in achieving specific goals and improving their performance, it appears that differentiation had a positive and significant impact on student learning as they benefited more and performed better than those students who attended traditional teaching. However, a study was found that showed that while differentiated instruction provided students with incentives to learn, there was no improvement in their grades. It also appears that a small number of researches have been identified in this field in higher education internationally, while no research has been conducted in Greece. Consequently, there is a need for further exploration of this variable in the international field and in Greece and in more teaching subjects.

Regarding the attitudes and beliefs of preservice teachers in differentiated instruction few researches have been found internationally while in Greece no research was found. Moreover, from the researches that have been examined the positive beliefs and attitudes of preservice teachers are shown, as they better understand the concept of differentiated instruction and by increasing their learning motivation as well as through reflection they supported the effectiveness of their differentiated instruction in their curriculum. However, two studies were identified, with the first recording that the novice teachers felt that the program they took part in had little contribution in their learning to teach Science and Mathematics with differentiated instruction, and the second that not all students were satisfied from the implementation of differentiated instruction. Most of the students who made positive comments about differentiation noted the increased interest of the teacher, which influenced them positively, while others thought that differentiation was a waste of time.

Also, regarding the attitudes and beliefs of preservice teachers educators in higher education, the number of researches identified and examined is very small, while no research has been found in Greece. As a result, there is a need for more investigation of this issue in Greece and internationally. Furthermore, from the researches which have been examined, the development of positive beliefs and attitudes of teachers towards acquiring new knowledge for teaching differentiation as they deepened their holistic understanding of the model and resolved their misunderstandings is shown. Also, differentiated instruction has been a 
challenge for educators as they need to better understand its educational strategies and how to implement them.

Concerning the advantages of implementing differentiated instruction in higher education, several studies have been identified in the international field and none in Greece. Therefore, in exploring the benefits of implementing differentiated instruction, there is a need for further research, particularly in the Greek field.

The most important advantages of implementing differentiated instruction are the focus on the learner who is actively involved in teaching, the reflection through which some teachers take direct initiatives in their classrooms, the increased interest of the teacher, the various methods in which teachers differentiate the content, process, product and environment, the effectiveness of teaching and the professional and academic success of preservice teachers.

About the difficulties arising from the implementation of differentiated instruction in higher education, a small number of studies were identified internationally, while no research was conducted in Greece. Consequently, there is a need for further research in the international as well as in the Greek field in exploring the difficulties in implementing differentiated instruction.

The most important difficulties mentioned in implementing differentiated instruction by preservice teachers are the large number of trainees in the classroom, the lack of time for careful planning of teaching, the limited space for teamwork, the difficulties in organizing and teaching content, the insecurity of taking initiatives by some teachers and lack of administrative support.

Concerning the conditions and procedures for the effective implementation of differentiated instruction in higher education, few researches have been examined internationally, and no research has been examined in Greece. Therefore, there is a need for further investigation of this issue mainly in Greece but also internationally. The most important prerequisites for effective implementation of differentiated instruction include careful planning and organization of teaching, knowledge of differentiated instruction, availability of time, flexibility on the part of the teacher and support from the administration.

Regarding the methodological design used in the examined studies on the implementation of differentiated instruction in higher education internationally, most researches implemented the qualitative and the mixed method, while less the quantitative and even less the Action Research, Quasi-experimental research, Self-Study research and Teaching. Regarding the sample size, most researches used a sample consisting of fewer than 50 individuals. Three researches using a sample ranging from 50-100 individuals were also found and four researches using a sample of more than one hundred individuals.

Concerning the cognitive subjects in which differentiated instruction has been implemented in higher education internationally and the purpose of its implementation, it is observed that most researches have been implemented in the Mathematics course followed by other courses such as Science, Education and Psychology of Excellent Students, School Experience, Reading, Computer Science, Teacher Certification Programs, Educational Psychology, 
Language Arts, Humanities and Social Sciences and the Arts.

Regarding the purpose of implementing differentiated instruction, it appears that the studies have investigated the effectiveness of implementing differentiated instruction in higher education. More specifically, several studies have focused on the perceptions of participating preservice teachers and their educators and some have examined the extent to which preservice teachers were familiar with the implementation of the specific teaching practice and the benefits they gained.

\section{Restrictions}

The constraints of this research include the small number of studies under consideration, the search for specific databases, and the focus on specific issues of the differentiated instruction in higher education.

\section{Suggestions}

Suggestions for further research could be the theoretical and practical exploration of other issues related to the differentiated instruction, such as teachers' training needs regarding its implementation. Furthermore, by conducting comparative researches at various levels of education in the educational system of Greece on the results of its implementation and its impact on learners and teachers, valuable conclusions will be drawn on the mobilization and improvement of trainees' performance, on the attitudes and beliefs of trainees and educators, as well as on the advantages and the difficulties, as well as the conditions for effective implementation of the differentiated instruction.

\section{References}

Anderson, K. M. (2007). Tips for teaching: Differentiating instruction to include all students. Preventing School Failure, 51(3), 49-53. https://doi.org/10.3200/PSFL.51.3.49-54

Bianchini, J. A., \& Brenner, M. E. (2009). The role of induction in learning to teach toward equity: A study of beginning science and mathematics teachers. Science Education, 94, 164-195. https://doi.org/10.1002/sce.20353

Buck, G. A., \& Cordes, J. (2005). An action research project on preparing teachers to meet the needs of underserved student populations. Journal of Science Teacher Education, 16(1), 43-64. https://doi.org/10.1007/ s10972-005-6991-x.

Butler, M., \& Van Lowe, K. (2010). Using differentiated instruction in teacher education. Retrieved from: http://www.cimt.org.uk/journal/butler.pdf

Chamberlin, M., \& Powers, R. (2010). The promise of differentiated instruction for enhancing the mathematical understandings of college students. Teaching Mathematics 
and Its Applications, 29, 113-139. https://doi.org/10.1093/teamat/hrq006

Chen, J. H., \& Chen, Y. C. (2018). Differentiated Instruction in a Calculus Curriculum for College Students in Taiwan. Journal of Education and Learning, 7(1) 88-95. https://doi.org/10.5539/jel.v7n1p88

Dack, H. (2015). Novice teachers' conceptions of differentiated instruction and related practice. Dissertation, University of Virginia. https://doi.org/10.18130/v3wk1m

Dosch, M., \& Zidon, M. (2014). The Course Fit Us": Differentiated instruction in the college classroom. International Journal of Teaching and Learning in Higher Education, 26(3), 343-357.

Ernst, H. R., \& Ernst, T. L. (2005). The promise and pitfalls of differentiated instruction for undergraduate political science courses: Student and instructor impressions of an unconventional teaching strategy. Journal of Political Science Education, 1, 39-59. https://doi.org/0.1080/15512160590907513

Evans-Hellman, L.A., \& Haney, R. (2017). Differentiation (DI) in Higher Education (HE): Modeling What We Teach with Pre-Service Teachers. Journal of Higher Education Theory and Practice, 17(5), 28-38.

Ford, N., Chen, S. Y. (2001). Matching/ mismatching revisited: an empirical study of learning and teaching styles. British Journal of Educational Technology, 32(1), 5-22. https://doi.org/10.1111/1467-8535.00173

Gardner, H. (1993). Multiple Intelligences: The Theory in Practice. New York: Basic Books.

Goodnough, K. (2010). Investigating pre-service science teachers' developing professional knowledge through the lens of differentiated instruction. Research in Science Education, 40, 239-265. https://doi.org/10.1007/s11165-009-9120-6

Graham, K. J. (2009). Mandated implementation of differentiated instruction effectiveness examined (Doctoral dissertation). Retrieved from ProQuest Dissertations and Theses database.

Hertberg-Davis, H. L., \& Brighton, C. M. (2006). Support and sabotage: Principals' influence on middle school teachers' responses to differentiation. Journal of Secondary Gifted Education, 17(2), 90-102. https://doi.org/10.4219/jsge-2006-685

Jackson, N., \& Evans, L. (2017). Self-Reflections on Differentiation: Understanding How We Teach in Higher Education. Networks, 19(1), 1-19. https://doi.org/10.4148/2470-6353.1012

Joseph, S. (2013). Differentiating instruction: Experiences of pre-service and in-service trained teachers. Caribbean Curriculum, 20, 31-51.

Knopper, D., \& Fertig, C. (2005). Differentiation for gifted children: It's all about trust. Illinois Association for Gifted Children Journal, 6(1), 6-8. 
Kosivaki, F. (2002). Critical Communication Teaching. Athens: Gutenberg

Mok, H. N. (2012). Student usage patterns and perceptions for differentiated lab exercises in an undergraduate programming course. IEEE Transactions on Education, 55(2), 213-217. https://doi.org/10.1109/te.2011.2162070

Panteliadou, S. (2008). Teaching Approaches and Practices for Students with Learning Disabilities. Volos.

Santangelo, T., \& Tomlinson, C. A. (2009). Teacher educators' perceptions and use of differentiated instruction practices: An exploratory investigation. Action in Teacher Education, 34, 309-327. https://doi.org/10.1080/01626620.2012.717032

Subban, P. (2006). Differentiated instruction: a research basis. International Education Journal, 7, 935-947.

Symeonidou, S., \& Kyriakides, E. (2010). Diversification in the language course: Opportunities and limitations of the School Experience course. 11th Congress of the Educational Society of Cyprus.

Tieso, C. (2004) Through the looking glass: One school's reflections on differentiation. Gifted Child Today, 27(4), 58-62. https://doi.org/10.4219/gct-2004-155

Tomlinson, C. (1999). The Differentiated Classroom: Responding to the Needs of All Learners ASCD. Alexandria: VA.

Tomlinson, C. A. (2001). How to differentiate instruction in mixed-ability classrooms (2nd ed.). Alexandria, VA: Association for Supervision and Curriculum Development.

Tomlinson, C. A. (2005). Traveling the Road to Differentiation in Staff Development. Journal of Staff Development, 26(4), 8-12.

Tomlinson, C. A., \& Imbeau, M. B. (2010). Leading and managing a differentiated classroom. Alexandria, VA: Association for Supervision and Curriculum Development.

Tomlinson, C. A., Brighton, C., Hertberg, H., Callahan, C. M., Moon, T. R., Brimijoin, K., Conover, L. A. \& Reynolds, T. (2003). Differentiating instruction in response to student readiness, interest, and learning profile in academically diverse classrooms: a review of literature. Journal for the Education of the Gifted, 27, 119-145. https://doi.org/10.1177/016235320302700203

Tricarico, K., \& Yendol-Hoppey, D. (2012). Teacher learning through self-regulation: An exploratory study of alternatively prepared teachers' ability to plan differentiated instruction in an urban elementary school. Teacher Education Quarterly, 39(1), 139-158.

Tulbure, C. (2011). Differentiate instruction for preservice teachers: An experimental investigation. Procedia-Social and Behavioral Sciences, 30, 448-452. https://doi.org/10.1016/j.sbspro.2011.10.088

Turner, W. D., Solis, O. J., \& Kincade, D.H. (2017). Differentiating Instruction for Large 
Classes in Higher Education. International Journal of Teaching and Learning in Higher Education, 29(3), 490-500.

Vygotsky, L. (1986). Thought and language. Boston: MIT Press.

Williams-Black, T. H., Bailey, J. P., \& Lawson, P. D. C. (2010). Differentiated instruction: Are university reading professors implementing it? The Reading Matrix, 10(1), 45-54.

\section{Copyright Disclaimer}

Copyright for this article is retained by the author(s), with first publication rights granted to the journal.

This is an open-access article distributed under the terms and conditions of the Creative Commons Attribution license (http://creativecommons.org/licenses/by/3.0/). 